JPE 12-2-9

http://dx.doi.org/10.6113/JPE.2012.12.2.305

\title{
Fuzzy Logic Speed Controller of 3-Phase Induction Motors for Efficiency Improvement
}

\author{
Emad Abdelkarim ${ }^{\dagger}$, Mahrous Ahmed ${ }^{*, * *}$, Mohamed Orabi $^{*}$, and Peter Mutschler ${ }^{* * *}$ \\ $\dagger^{*}$ Dept. of Electrical Eng., South Valley University, Aswan, Egypt \\ ${ }^{* *}$ Dept. of Electrical Eng., Taif University, Saudi Arabia \\ ${ }^{* * *}$ Power Electronics and Control of Drives Institute, Darmstadt University of Technology, Germany
}

\begin{abstract}
The paper presents an accurate loss model based controller of an induction motor to calculate the optimal air gap flux. The model includes copper losses, iron losses, harmonic losses, friction and windage losses, and stray losses. These losses are represented as a function of the air gap flux. By using the calculated optimal air gap flux compared with rated flux for speed sensorless indirect vector controlled induction motor, an improvement in motor efficiency is achieved. The motor speed performance is improved using a fuzzy logic speed controller instead of a PI controller. The fuzzy logic speed controller was simulated using the fuzzy control interface block of MATLAB/SIMULINK program. The control algorithm is experimentally tested within a PC under RTAI-Linux. The simulation and experimental results show the improvement in motor efficiency and speed performance.
\end{abstract}

Key words: Fuzzy Logic Control, Induction Motor Efficiency, Loss Model Control, Speed Control, Three Phase VSI

\section{NOMENCLATURE}

$\mathrm{R}_{\mathrm{s}}$ : stator resistance

$\mathrm{R}_{\mathrm{r}}$ : rotor resistance (referred to stator side)

$\mathrm{R}_{\text {str }}$ : Stray resistance

$\mathrm{R}_{\mathrm{fe}}$ : magnetic loss resistance

$\mathrm{X}_{\mathrm{s}}$ : stator leakage reactance

$\mathrm{X}_{\mathrm{r}}$ : rotor leakage reactance (referred to stator side)

$\mathrm{X}_{\mathrm{m}}$ : magnetizing leakage reactance

S1, S2, S3: magnetizing curve coefficients

$\mathrm{C}_{\mathrm{fw}}$ : friction and windage coefficient

$\mathrm{K}_{\mathrm{e}}, \mathrm{K}_{\mathrm{h}}$ : eddy and hysteresis coefficients, respectively

P: motor pole pairs

$\phi:$ air gap flux

$\phi_{\text {opt: }}$ optimal air gap flux

n: rotor speed

$\omega$ : angular motor speed $=2 \pi \mathrm{n}$

s: slip

$\mathrm{I}_{\mathrm{s}}$ : stator current

$\mathrm{I}_{\mathrm{r}}$ : rotor current

$\mathrm{I}_{\mathrm{m}}$ : magnetizing current

Manuscript received Nov. 22, 2011; revised Feb. 4, 2012

Recommended for publication by Associate Editor Jung-Ik Ha.

${ }^{\dagger}$ Corresponding Author: meahmed7@ieee.org

Tel: +20-97-466-1589, Fax: +20-97-466-1589, South Valley Univ.

*Dept. of Electrical Eng., South Valley University, Egypt

${ }^{* *}$ Dept. of Electrical Eng., Taif University, Saudi Arabia

${ }^{* * *}$ Power Electronics and Control of Drives Institute, Darmstadt

University of Technology, Germany

\section{INTRODUCTION}

The electricity bill of a motor for some months has increased more than its original cost and, therefore, even a small efficiency improvement will produce notable cost saving. With the advantages of low price and reliability, induction motors are widely used in the industry. Improved efficiency of the three-phase induction motor is considered to be a major subject for energy savings, as most of the electrical power consumed in industry is used in induction motors.

The efforts on efficiency improvement are divided into two major directions: 1) improving the motor and converter design [1], [2] (not available for motors under operation); 2) introducing control strategies based on optimal air gap flux which reduce the motor losses. The second technique will be considered in this paper.

Search Control method (SC) and Loss Model based Controller (LMC) [3]-[13] are two different approaches to find the optimal air gap flux. In a search controller, the air gap flux is varied till the minimum input power is detected for the actual operating condition, i.e. load torque and speed [3],[4]. The measured motor input power is used as a feedback quantity for the SC. The drawbacks of the SC are: 1) input power has to be measured; 2) slow convergence and 
torque variations; and 3) the speed sensor is mandatory [6].

The LMC calculates the optimal air gap flux depending on the estimation of the total motor losses. LMC is a feed-forward approach. Many loss models [5]-[13] are used for efficiency improvement, but the differences among them depend on the accuracy and simplicity of the model due to the neglect of certain loss types (such as harmonic, friction, or stray loss), the effect of saturation, or the effect of parameters variation. The optimal efficiency point is found by equating the losses related to the torque producing current to the losses related with the field producing current using a PI-controller [5] , [6]. However, it is not clear how to tune the PI parameters. A loss model including only copper loss and saturation effects are discussed in [7] while neglecting the other losses for simplicity. The optimal air gap flux is calculated by balancing copper and iron losses [8] regardless of the other losses. The proposed loss model in [9] includes the different motor losses but neglects the saturation and temperature effects. A loss-minimization algorithm is developed [10] to achieve maximum efficiency in terms of slip frequency. The optimal value of slip frequency can be obtained by minimizing all controllable losses of the IM. The ratio of the magnetic energy (converted to torque) to magnetic energy (stored in the rotating field) is defined in terms of slip frequency to obtain an error function that is used to design a controller to achieve the desired speed. This loss model only includes the copper losses, core losses and stray losses. Optimal-loss-minimization algorithm is investigated in the high-speed region in [11]. This model consists of the copper and the core losses and neglects the leakage inductance which plays a great role in the high-speed region. The accuracy of this model is still low since most of different losses is neglected. A hybrid method is proposed in [12] and [13] using an LMC and SC. The first estimation is from the LMC and the subsequent adjustment of the flux is through the SC. As a result, it needs an accurate on-line power measuring device which leads to extra cost.

The LMC, like all feed-forward methods, is sensitive to model inaccuracies and parameters variation. In this paper, a new and accurate expression for the optimal flux is calculated from a rather detailed loss model, where copper losses, iron losses, harmonic losses, friction and windage losses as well as stray losses are included. Additionally, the non-linearity of the magnetizing inductance and the effect of the temperature on stator and rotor resistances are considered.

The paper is organized as follows. Firstly, the IM variables and model are presented. In Section III subsequently presents the proposed LMC. Section IV presents a comparison between Fuzzy logic controller (FLC) and PI controller from the motor speed performance point of view. Then, Section V provides the simulation results using MATLAB/SIMULINK. Section VI gives experimental results to validate the performance of the proposed LMC. The control algorithm is

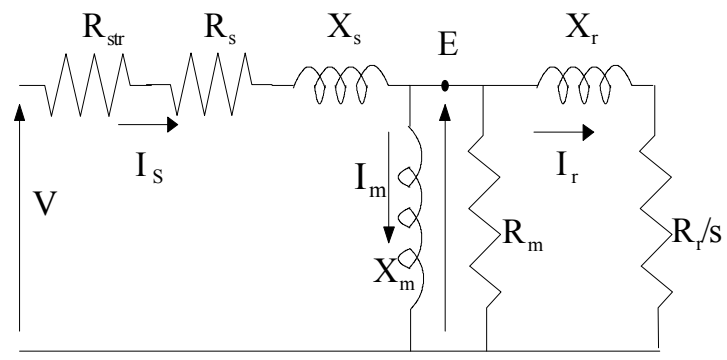

Fig. 1. Induction motor equivalent circuit.

experimentally tested within a PC under RTAI-Linux. Lastly, Section VII summarizes the proposed new LMC concepts proposed in the paper.

\section{INDUCTION MOTOR CIRCUIT MODEL}

The motor variables such as stator current, rotor current, magnetizing current and electromagnetic torque are described as functions in air gap flux. The single-phase equivalent circuit of the induction motor at steady state is shown in Fig. 1. From the equivalent circuit, the following expressions are deduced

$$
\mathrm{E}=\omega_{\mathrm{s}} \phi, \mathrm{I}_{\mathrm{m}}=\omega_{\mathrm{s}} \phi / \mathrm{X}_{\mathrm{m}}
$$

As the magnetizing reactance becomes highly nonlinear, the magnetizing current and magnetizing reactance are expressed as follows:

$$
\begin{gathered}
\mathrm{I}_{\mathrm{m}}=\mathrm{S}_{1} \phi+\mathrm{S}_{2} \phi^{3}+\mathrm{S}_{3} \phi^{5} \\
\mathrm{X}_{\mathrm{m}}=\omega_{\mathrm{s}} /\left(\mathrm{S}_{1}+\mathrm{S}_{2} \phi^{2}+\mathrm{S}_{3} \phi^{4}\right)
\end{gathered}
$$

The rotor current expression is given by (4).

$$
I_{r}=E / \sqrt{\left(\frac{R_{r}}{s}\right)^{2}+X_{r}^{2}}=\omega_{s} \phi / \sqrt{\left(\frac{R_{r}}{s}\right)^{2}+X_{r}^{2}}
$$

The IM operates with a small slip, so $\left(\mathrm{R}_{\mathrm{r}} / s\right)^{2} \gg \mathrm{X}_{\mathrm{r}}^{2}$ holds and the rotor current is approximately calculated as follows:

$$
\mathrm{I}_{\mathrm{r}} \cong \mathrm{s} \omega_{\mathrm{s}} \phi / \mathrm{R}_{\mathrm{r}}
$$

The electromagnetic torque equation is given by (6)

$$
\mathrm{T}=\mathrm{I}_{\mathrm{r}}^{2} \frac{\mathrm{R}_{\mathrm{r}}}{\omega} \frac{1-\mathrm{s}}{\mathrm{s}}=\mathrm{PI}_{\mathrm{r}}^{2} \frac{\mathrm{R}_{\mathrm{r}}}{\omega_{\mathrm{e}}} \frac{1-\mathrm{s}}{\mathrm{s}}
$$

And the slip is given by (7).

$$
\mathrm{s}=\left(\omega_{\mathrm{s}}-\omega_{\mathrm{e}}\right) / \omega_{\mathrm{s}}
$$

From (5), (6), and (7), the electromagnetic torque becomes

$$
\mathrm{T}=\mathrm{P} \phi^{2} \frac{\mathrm{s} \omega_{\mathrm{s}}}{\mathrm{R}_{\mathrm{r}}}
$$

For simplicity, the effect of the rotor leakage reluctance $X_{r}$ is neglected. As a result, $\mathrm{R}_{\mathrm{m}}$ becomes in parallel with the rotor resistance $\mathrm{R}_{\mathrm{r}} / \mathrm{s}$. Also as $\left.\left.\mathrm{R}_{\mathrm{r}} / \mathrm{s}\right\rangle\right\rangle \mathrm{R}_{\mathrm{m}}$, the current in $\mathrm{R}_{\mathrm{m}}$ branch can be neglected compared with the rotor current. Thus the stator current becomes:

$$
\mathrm{I}_{\mathrm{s}}^{2} \cong \mathrm{I}_{\mathrm{r}}^{2}+\mathrm{I}_{\mathrm{m}}^{2}
$$

Substituting from (1) and (5) into (9), the stator current 
becomes:

$$
\mathrm{I}_{\mathrm{s}}^{2} \cong\left(\frac{\mathrm{s} \omega_{\mathrm{s}}}{\mathrm{R}_{\mathrm{r}}}\right)^{2} \phi^{2}+\left(\frac{\omega_{\mathrm{s}}}{\mathrm{X}_{\mathrm{m}}}\right)^{2} \phi^{2}
$$

\section{THE PROPOSED LOSS MOdEL CONTROLlER}

In the proposed LMC, the losses of the IM are calculated as follows:

1) Copper losses: They refer to the ohmic losses in the stator and rotor winding. Temperature and influence of skin effect in the winding would be necessary for a correct copper losses calculation. To circumvent this problem, the stator and rotor resistances are estimated on-line by adaptive motor parameter observer [14]. The stator and rotor copper losses then can be calculated from (11).

$$
P_{c u, s}=3 I_{s}^{2} R_{s}, P_{c u, r}=3 I_{r}^{2} R_{r}
$$

2) Iron losses: They refer to energy losses in magnetizing of the steel laminations which consists of eddy current losses and hysteresis losses. They are governed by (12).

$$
\mathrm{P}_{\mathrm{fe}}=\left(\mathrm{K}_{\mathrm{e}}\left(1+\mathrm{s}^{2}\right) \omega_{\mathrm{s}}^{2}+\mathrm{K}_{\mathrm{h}}(1+\mathrm{s}) \omega_{\mathrm{s}}\right) \phi^{2}
$$

3) Friction and windage losses: They refer to energy losses in bearing friction, cooling fans, and windage of other rotating parts. These losses are represented as a function of the motor speed $[1,8]$ and they are given by (13).

$$
\mathrm{P}_{\mathrm{fw}}=\mathrm{C}_{\mathrm{fw}} \omega^{2}
$$

4) Harmonic losses: Harmonic power losses are the difference between the total motor input power and the fundamental power. Thus it is very difficult to find a closed formula for harmonic power losses. To overcome this problem, harmonic power losses have been measured at different speeds and different load torques. Fig. 2 shows the measured harmonic power losses in the tested $2.2 \mathrm{~kW}$ induction motor for different speeds and load torques at rated flux. Depending on these results, the motor harmonic losses are assumed to be approximately $1 \%$ of the motor rated power.

5) Stray losses: They are related to the construction of the motor parts that do not produce the output power in or near the magnetic fields, and interaction of magnetic fields in the motor. These losses are represented by the resistance $\left(\mathrm{R}_{\text {str }}\right)$ in the stator branch. Another expression for the stray losses is given by equation (14).

$$
\mathrm{P}_{\mathrm{str}}=\mathrm{C}_{\mathrm{str}} \omega^{2} \mathrm{I}_{\mathrm{r}}^{2}
$$

This expression holds for dc motors and is also acceptable for induction motors as well [9]. The total motor power losses are the sum of the above losses and are given by (15).

$$
\begin{aligned}
\mathrm{P}_{\text {loss }} & =\mathrm{P}_{\mathrm{cu}, \mathrm{s}}+\mathrm{P}_{\mathrm{cu}, \mathrm{r}}+\mathrm{P}_{\mathrm{str}}+\mathrm{P}_{\mathrm{fe}}+\mathrm{P}_{\mathrm{fw}}+\mathrm{P}_{\mathrm{h}} \\
& =\mathrm{I}_{\mathrm{s}}^{2} \mathrm{R}_{\mathrm{s}}+\mathrm{I}_{\mathrm{r}}^{2} \mathrm{R}_{\mathrm{r}}+\mathrm{C}_{\mathrm{str}} \omega^{2} \mathrm{I}_{\mathrm{r}}^{2}+\left(\mathrm{K}_{\mathrm{e}} \omega_{\mathrm{s}}^{2}+\mathrm{K}_{\mathrm{h}} \omega_{\mathrm{s}}\right) \phi^{2}+\mathrm{C}_{\mathrm{fw}} \omega^{2}+\mathrm{P}_{\mathrm{h}}
\end{aligned}
$$

Combining (5) and (10) into (11), the total power losses become:

$$
\begin{aligned}
& P_{\text {loss }}=\phi^{2}\left(\mathrm{R}_{\mathrm{s}}\left(\left(\frac{\mathrm{s} \omega_{\mathrm{s}}}{\mathrm{R}_{\mathrm{r}}}\right)^{2}+\left(\frac{\omega_{\mathrm{s}}}{\mathrm{X}_{\mathrm{m}}}\right)^{2}\right)+\mathrm{R}_{\mathrm{r}}\left(\frac{\mathrm{s} \omega_{\mathrm{s}}}{\mathrm{R}_{\mathrm{r}}}\right)^{2}\right)+ \\
& \phi^{2}\left(\mathrm{C}_{\mathrm{str}} \omega^{2}\left(\frac{\mathrm{s} \omega_{\mathrm{s}}}{\mathrm{R}_{\mathrm{r}}}\right)^{2}+\left(\mathrm{K}_{\mathrm{e}} \omega_{\mathrm{s}}^{2}+\mathrm{K}_{\mathrm{h}} \omega_{\mathrm{s}}\right)\right)+\mathrm{C}_{\mathrm{fw}} \omega^{2}+\mathrm{P}_{\mathrm{h}}
\end{aligned}
$$

From (8), the flux is calculated as given by equation (17).

$$
\phi^{2}=\frac{1}{\mathrm{P}} \frac{\mathrm{TR}}{\mathrm{s} \omega_{\mathrm{S}}}
$$

Using (3), (16), and (17), the total power losses as a function of torque is governed by (18).

$$
\begin{aligned}
& \mathrm{P}_{\text {loss }}=\frac{1}{\mathrm{P}} \mathrm{TR}_{\mathrm{r}} \mathrm{s} \omega_{\mathrm{s}}\left(\frac{\mathrm{R}_{\mathrm{s}}}{\mathrm{R}_{\mathrm{r}}^{2}}+\frac{1}{\mathrm{R}_{\mathrm{r}}}+\frac{\mathrm{C}_{\mathrm{str}} \omega^{2}}{\mathrm{R}_{\mathrm{r}}^{2}}\right)+\frac{1}{\mathrm{P}} \frac{\mathrm{TR} \mathrm{r}}{\mathrm{s} \omega_{\mathrm{s}}} * \\
& \left(\mathrm{R}_{\mathrm{s}}\left(\mathrm{S}_{1}+\mathrm{S}_{2} \frac{1}{\mathrm{P}} \frac{\mathrm{TR} \mathrm{r}}{\mathrm{s} \omega_{\mathrm{s}}}+\mathrm{S}_{3}\left(\frac{1}{\mathrm{P}} \frac{\mathrm{TR} \mathrm{r}}{\mathrm{s} \omega_{\mathrm{s}}}\right)^{2}\right)^{2}\right)+\frac{1}{\mathrm{P}} \frac{\mathrm{TR} \mathrm{r}}{\mathrm{s} \omega_{\mathrm{s}}} * \\
& \left(\mathrm{~K}_{\mathrm{e}} \omega_{\mathrm{s}}^{2}+\mathrm{K}_{\mathrm{h}} \omega_{\mathrm{s}}\right)+\mathrm{C}_{\mathrm{fw}} \omega^{2}+\mathrm{P}_{\mathrm{h}}
\end{aligned}
$$

The inverse of slip speed variable $(\mathrm{X})$ is introduced which is defined as:

$$
X=\frac{1}{s \omega_{S}}
$$

Inserting (19) in (18) results in:

$$
\begin{aligned}
& \mathrm{P}_{\text {loss }}=\frac{1}{\mathrm{P}} \frac{\mathrm{TR}}{\mathrm{X}}\left(\frac{\mathrm{R}_{\mathrm{s}}}{\mathrm{R}_{\mathrm{r}}^{2}}+\frac{1}{\mathrm{R}_{\mathrm{r}}}+\frac{\mathrm{C}_{\mathrm{str}} \omega^{2}}{\mathrm{R}_{\mathrm{r}}^{2}}\right)+\frac{\mathrm{TR}_{\mathrm{r}} \mathrm{X}}{\mathrm{P}} * \\
& \left(\mathrm{R}_{\mathrm{s}}\left(\mathrm{S}_{1}+\mathrm{S}_{2} \frac{\mathrm{TR}_{\mathrm{r}} \mathrm{X}}{\mathrm{P}}+\mathrm{S}_{3}\left(\frac{\mathrm{TR} \mathrm{R}}{\mathrm{P}}\right)^{2}\right)^{2}\right)+\frac{\mathrm{TR}_{\mathrm{r}} \mathrm{X}}{\mathrm{P}} * \\
& \left(\mathrm{~K}_{\mathrm{e}}\left(\frac{1}{\mathrm{X}}+\omega_{\mathrm{e}}\right)^{2}+\mathrm{K}_{\mathrm{h}}\left(\frac{1}{\mathrm{X}}+\omega_{\mathrm{e}}\right)\right)+\mathrm{C}_{\mathrm{fw}} \omega^{2}+\mathrm{P}_{\mathrm{h}} \\
& \text { Let, } \mathrm{C}_{1}=\frac{\mathrm{T} \mathrm{R}_{\mathrm{r}}}{\mathrm{P}}, \quad \mathrm{C}_{2}=\left(\frac{\mathrm{R}_{\mathrm{s}}}{\mathrm{R}_{\mathrm{r}}^{2}}+\frac{1}{\mathrm{R}_{\mathrm{r}}}+\frac{\mathrm{C}_{\mathrm{str}} \omega^{2}}{\mathrm{R}_{\mathrm{r}}^{2}}\right)
\end{aligned}
$$

Thus equation (20) becomes:

$$
\begin{aligned}
& \mathrm{P}_{\text {loss }}=\frac{\mathrm{C}_{1} \mathrm{C}_{2}}{\mathrm{X}}+\mathrm{C}_{1} \mathrm{X}\left(\mathrm{R}_{\mathrm{s}}\left(\mathrm{S}_{1}+\mathrm{S}_{2} \mathrm{C}_{1} \mathrm{X}+\mathrm{S}_{3}\left(\mathrm{C}_{1} \mathrm{X}\right)^{2}\right)^{2}\right)+ \\
& \mathrm{C}_{1} \mathrm{X}\left(\mathrm{K}_{\mathrm{e}}\left(\frac{1}{\mathrm{X}}+\omega_{\mathrm{e}}\right)^{2}+\mathrm{K}_{\mathrm{h}}\left(\frac{1}{\mathrm{X}}+\omega_{\mathrm{e}}\right)\right)+\mathrm{C}_{\mathrm{fw}} \omega^{2}+\mathrm{P}_{\mathrm{h}}
\end{aligned}
$$

The loss minimization with respect to the flux at steady state is calculated according to the following condition:

$$
\left.\frac{\mathrm{dP}_{\mathrm{loss}}}{\mathrm{d} \phi}\right|_{\mathrm{T}, \omega}=0 .
$$

From (8) and (19), the electromagnetic torque becomes:

$$
\mathrm{T}=\frac{\mathrm{P}}{\mathrm{R}_{\mathrm{r}}} \phi^{2} \frac{1}{\mathrm{X}}
$$

During steady state, the electromagnetic torque is constant, thus $\mathrm{dT} / \mathrm{d} \phi=0$.

Taking $d T / d \phi$ of (23) results in; 


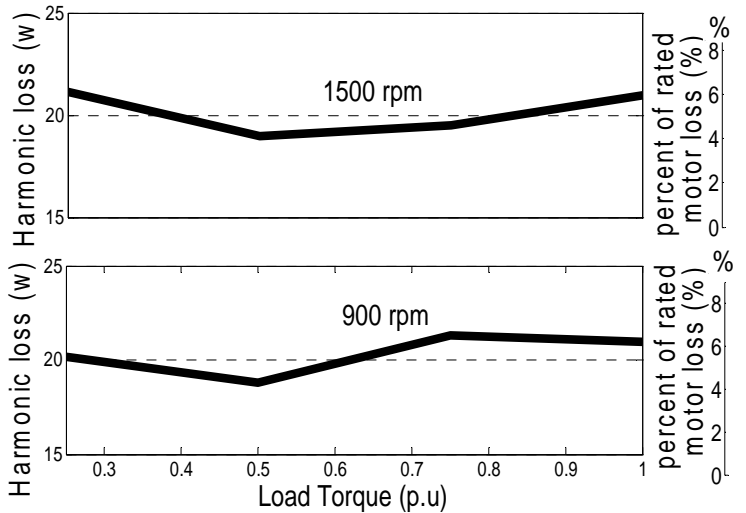

Fig. 2. Measured harmonic power losses for 1500 and 900 rpm.

$$
\frac{\mathrm{dT}}{\mathrm{d} \phi}=\frac{\mathrm{P}}{\mathrm{R}_{\mathrm{r}}}\left(2 \frac{1}{\mathrm{X}}-\phi^{2} \frac{1}{\mathrm{X}^{2}} \frac{\mathrm{dX}}{\mathrm{d} \phi}\right)=0 \rightarrow \mathrm{d} \phi=\frac{\phi}{2 \mathrm{X}} \mathrm{dX}
$$

From (22) and (23), the new criterion to get minimum loss can be emerged as follows:

$$
\mathrm{dP}_{\text {loss }} / \mathrm{dX}=0
$$

The derivation of (21) with respected to $(\mathrm{X})$ gives a sixth order polynomial function in $(\mathrm{X})$ as follows:

$$
\alpha_{0}+\alpha_{1} X+\alpha_{2} X^{2}+\alpha_{3} X^{3}+\ldots \ldots .+\alpha_{6} X^{6}=0
$$

The coefficients of this equation are functions of the motor parameters. Note that the speed and the electromagnetic torque will be estimated. By solving (26), the optimal value of $\mathrm{X}\left(\mathrm{X}_{\text {optimal }}\right)$ can be calculated. Then using (23), the optimal flux ( $\left.\phi_{\text {optimal }}\right)$ can be calculated as well.

$$
\phi_{\text {optimal }}=\sqrt{\frac{\mathrm{TR}_{\mathrm{r}} \mathrm{X}_{\text {optimal }}}{\mathrm{P}}}
$$

The electromagnetic torque (T) is calculated from (28) [1].

$$
\mathrm{T}=\frac{3}{2} \frac{\mathrm{P}}{2} \frac{\mathrm{L}_{\mathrm{m}}}{\mathrm{L}_{\mathrm{r}}} \mathrm{L}_{\mathrm{m}} \mathrm{i}_{\mathrm{qs}} \mathrm{i}_{\mathrm{ds}}
$$

The torque producing current component can be represented by $\mathrm{i}_{\mathrm{qs}}$, and the flux producing current component can be represented by $i_{d s}$. Fig. 3 shows the calculated optimal flux for an IM $(2.2 \mathrm{~kW}, 14 \mathrm{Nm}$ rated load torque, and $1420 \mathrm{rpm}$ rated speed) at different load torques and different required speeds (controlled reference speed). Fig. 4 shows the block diagram of the proposed controller of the IM.

The controller consists of four main blocks. The first block is the field oriented control to drive the motor as variable speed drive. The speed is sensorless estimated using the second block. The speed estimation block is updated each $100 \mu s$ (switching time) but the parameter adaptive observer is updated each minute since the temperature change is not so fast. In the third block the stator and rotor resistances are estimated by using parameter adaptive observer [14]. Finally

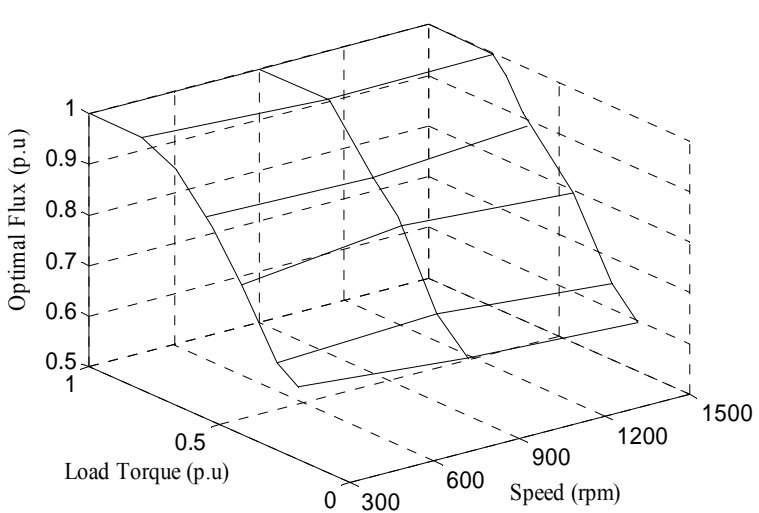

Fig. 3. Optimal air gap flux for different load torques at different speeds (300rpm to $1500 \mathrm{rpm}$ ).

the proposed LCM calculates the optimal air gap flux [15]-[17], and the reference optimal flux producing current component $\left(\mathrm{i}_{\mathrm{ds}(\mathrm{opt})}\right)$ is calculated from the calculated optimal air gap flux as given by (29).

$$
\mathrm{i}_{\mathrm{ds}(\mathrm{opt})}=\phi_{\mathrm{opt}} / \mathrm{L}_{\mathrm{m}}
$$

The LMC only works at steady state, while at transient the reference flux producing current component is set to the rated value. The block diagram of the speed estimation using the motor back EMF [18] is shown in Fig. 5. The speed is estimated from the rotor voltage and current equations as follows:

The rotor voltage equations in the stationary $(\alpha, \beta)$ frame are:

$$
\begin{aligned}
& \mathrm{R}_{\mathrm{r}} \mathrm{i}_{\alpha \mathrm{r}}+\rho \phi_{\alpha r}+\omega_{\mathrm{r}} \phi_{\beta r}=0 \\
& \mathrm{R}_{\mathrm{r}{ }_{\beta r}}+\rho \phi_{\beta r}-\omega_{\mathrm{r}} \phi_{\alpha r}=0
\end{aligned}
$$

Where $\rho=d / d t$

The rotor currents are governed by (31)

$$
\begin{aligned}
& \mathrm{i}_{\alpha \mathrm{r}}=\left(\alpha \mathrm{r}^{-} \mathrm{L}_{\mathrm{m}} \mathrm{i}_{\alpha \mathrm{s}}\right) / \mathrm{L}_{\mathrm{r}} \\
& \mathrm{i}_{\beta \mathrm{r}}=\left(\beta \mathrm{r}^{-} \mathrm{L}_{\mathrm{m}} \mathrm{i}_{\beta \mathrm{s}}\right) / \mathrm{L}_{\mathrm{r}}
\end{aligned}
$$

Resolving (30) and using (31), the speed can be estimated using (32) and (33).

$$
\omega_{\mathrm{r}}=\left(\rho \phi_{\beta r}+\frac{\mathrm{R}_{\mathrm{r}}}{\mathrm{L}_{\mathrm{r}}} \phi_{\beta \mathrm{r}}-\frac{\mathrm{R}_{\mathrm{r}} \mathrm{L}_{\mathrm{m}}}{\mathrm{L}_{\mathrm{r}}} \mathrm{i}_{\beta \mathrm{s}}\right) / \phi_{\alpha \mathrm{r}}=\mathrm{A} / \phi_{\alpha \mathrm{r}}
$$

Or,

$$
\omega_{\mathrm{r}}=\left(-\rho \phi_{\alpha r}-\frac{\mathrm{R}_{\mathrm{r}}}{\mathrm{L}_{\mathrm{r}}} \phi_{\alpha r}+\frac{\mathrm{R}_{\mathrm{r}} \mathrm{L}_{\mathrm{m}}}{\mathrm{L}_{\mathrm{r}}} \mathrm{i}_{\alpha \mathrm{s}}\right) / \phi_{\beta \mathrm{r}}=\mathrm{B} / \phi_{\beta \mathrm{r}}
$$

The rotor flux components are calculated from the stator flux and stator current components as follows:

$$
\phi_{\alpha \mathrm{r}}=\frac{\mathrm{L}_{\mathrm{r}}}{\mathrm{L}_{\mathrm{m}}}\left(\phi_{\alpha \mathrm{s}}-\sigma \mathrm{i}_{\alpha \mathrm{s}}\right), \phi_{\beta \mathrm{r}}=\frac{\mathrm{L}_{\mathrm{r}}}{\mathrm{L}_{\mathrm{m}}}\left(\phi_{\beta \mathrm{s}}-\sigma \mathrm{i}_{\beta \mathrm{s}}\right)
$$




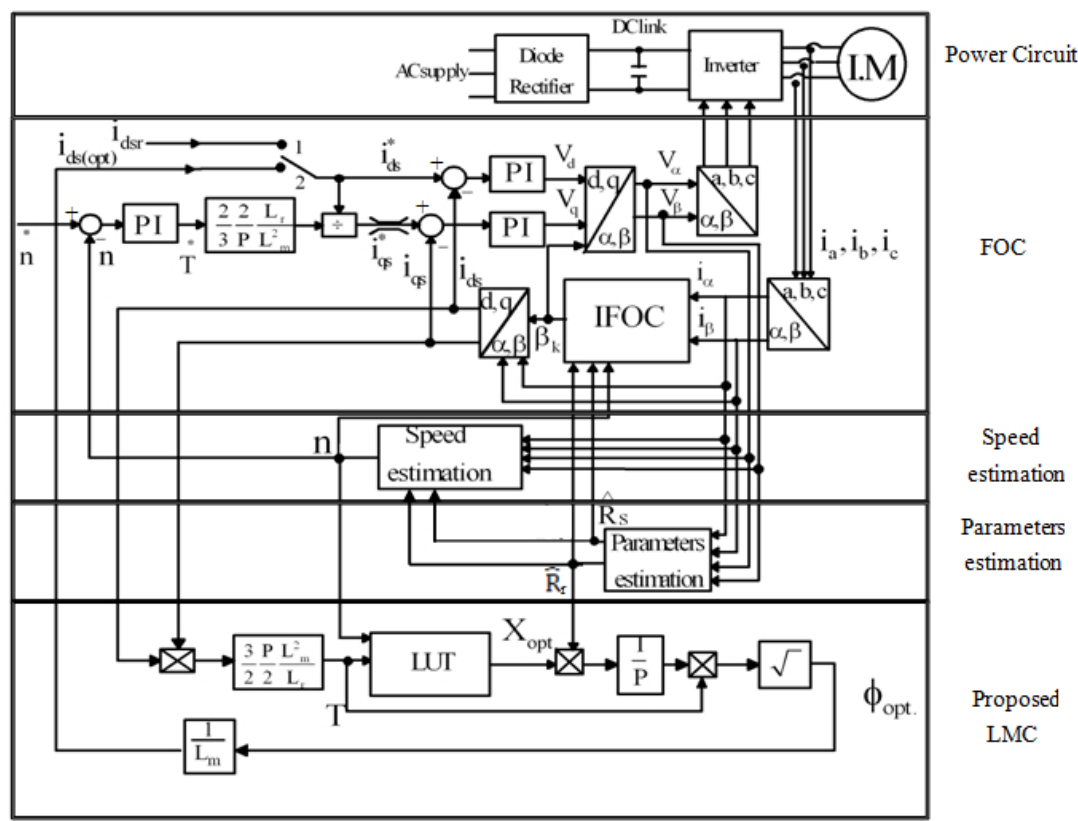

Fig. 4. Block diagram of loss model based controller for sensorless speed vector control induction motor.

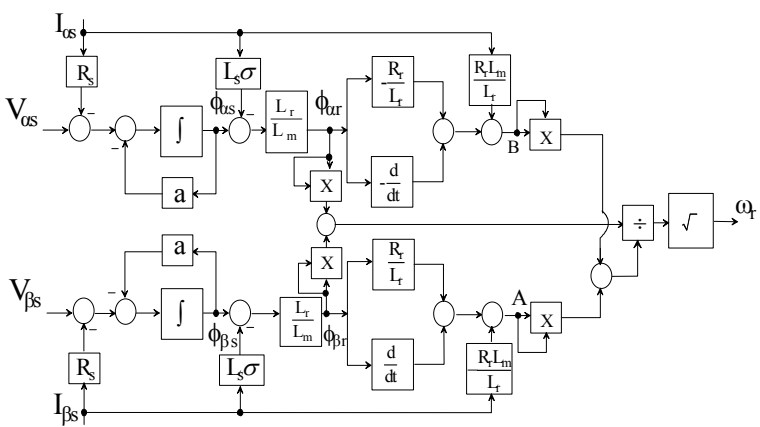

Fig. 5. Speed estimation block diagram.

$$
\text { And } \sigma=\left(\mathrm{L}_{\mathrm{s}} \mathrm{L}_{\mathrm{r}}-\mathrm{L}_{\mathrm{m}}^{2}\right) / \mathrm{L}_{\mathrm{s}}
$$

The stator flux is estimated by integrating the stator backEMF using a low pass filter in (32) and (33) and its value is represented by (34).

$$
\begin{aligned}
& \alpha_{\alpha s}=\left(V_{\beta s}-R_{s} i_{\alpha s}\right) /(s+a) \\
& \beta s=\left(V_{\beta s}-R_{s} i_{\beta s}\right) /(s+a)
\end{aligned}
$$

Where ' $a$ ' is the cut-off frequency ( $a=3 \mathrm{~Hz}$ ), and ' $\mathrm{s}$ ' is Laplace Operator. The numerator of (32) depends on the current component $\left(i_{\beta s}\right)$, and the numerator of (33) depends on the current component $\left(i_{\alpha s}\right)$. Nevertheless, the accurate calculation of each component differs from each other due to the different accuracy in measuring the three motor currents. Thus it is better and more accurate to include the two current components $\left(i_{\alpha s}, i_{\beta s}\right)$ in one equation as follows. Equation (32) can be rewritten as,

$$
\begin{array}{r}
\omega_{\mathrm{r}}=\frac{\mathrm{A}}{\phi_{\alpha \mathrm{r}}}=\frac{\mathrm{A}}{\phi_{\alpha \mathrm{r}}} \frac{\sqrt{\phi_{\alpha \mathrm{r}}^{2}+\phi_{\beta \mathrm{r}}^{2}}}{\sqrt{\phi_{\alpha \mathrm{r}}^{2}+\phi_{\beta \mathrm{r}}^{2}}} \\
\omega_{\mathrm{r}}=\frac{\sqrt{\frac{\mathrm{A}^{2}}{\phi_{\alpha \mathrm{r}}^{2}} \phi_{\alpha \mathrm{r}}^{2}+\frac{\mathrm{A}^{2}}{\phi_{\alpha \mathrm{r}}^{2}} \phi_{\beta \mathrm{r}}^{2}}}{\sqrt{\phi_{\alpha \mathrm{r}}^{2}+\phi_{\beta \mathrm{r}}^{2}}}
\end{array}
$$

Equations (32) and (33) can be modified as follows:

$$
\frac{\mathrm{A}}{\phi_{\alpha \mathrm{r}}}=\frac{\mathrm{B}}{\phi_{\beta \mathrm{r}}}
$$

By inserting (36) in (35), the estimated speed becomes

$$
\omega_{\mathrm{r}}=\frac{\sqrt{\mathrm{A}^{2}+\mathrm{B}^{2}}}{\sqrt{\phi_{\alpha \mathrm{r}}^{2}+\phi_{\beta \mathrm{r}}^{2}}}
$$

The parameter adaptive observer shown in Fig. 6 is used to estimate the stator and rotor resistances. The IM in the stationary reference frame is described by the state equation (38).

$$
\left[\begin{array}{c}
\dot{\mathrm{i}_{\mathrm{s}}} \\
\dot{\phi_{\mathrm{r}}}
\end{array}\right]=\left[\begin{array}{ll}
\mathrm{A}_{11} & \mathrm{~A}_{12} \\
\mathrm{~A}_{21} & \mathrm{~A}_{22}
\end{array}\right]\left[\begin{array}{l}
\mathrm{i}_{\mathrm{s}} \\
\phi_{\mathrm{r}}
\end{array}\right]+\left[\begin{array}{l}
\mathrm{B} \\
0
\end{array}\right] \mathrm{v}_{\mathrm{s}}
$$

Where,

$\mathrm{i}_{\mathrm{s}}=\left[\begin{array}{ll}\mathrm{i}_{\alpha \mathrm{s}} & \mathrm{i}_{\beta \mathrm{s}}\end{array}\right]^{\mathrm{T}}=$ Stator current

$\phi_{\mathrm{r}}=\left[\begin{array}{ll}\phi_{\alpha \mathrm{r}} & \phi_{\beta \mathrm{r}}\end{array}\right]^{\mathrm{T}}=$ Rotor flux

$\mathrm{v}_{\mathrm{s}}=\left[\begin{array}{ll}\mathrm{v}_{\alpha \mathrm{s}} & \mathrm{v}_{\beta \mathrm{s}}\end{array}\right]^{\mathrm{T}}:$ Stator voltage 


$$
\begin{aligned}
& \mathrm{A}_{11}=-\left\{\mathrm{R}_{\mathrm{s}} /\left(\sigma \mathrm{L}_{\mathrm{s}}\right)+(1-\sigma) /\left(\sigma \tau_{\mathrm{r}}\right)\right\} \mathrm{I}=\mathrm{a}_{\mathrm{r} 11} \mathrm{I} \\
& \mathrm{A}_{12}=\mathrm{L}_{\mathrm{m}} /\left(\sigma \mathrm{L}_{\mathrm{s}} \mathrm{L}_{\mathrm{r}}\right)\left\{1 /\left(\tau_{\mathrm{r}}\right) \mathrm{I}-\omega_{\mathrm{r}} \mathrm{J}\right\}=\mathrm{a}_{\mathrm{r} 12} \mathrm{I}+\mathrm{a}_{112} \mathrm{~J} \\
& \mathrm{~A}_{21}=\left(\mathrm{L}_{\mathrm{m}} / \tau_{\mathrm{r}}\right) \mathrm{I}=\mathrm{a}_{\mathrm{r} 21} \mathrm{I} \\
& \mathrm{A}_{22}=-\left(1 / \tau_{\mathrm{r}}\right) \mathrm{I}+\omega_{\mathrm{r}} \mathrm{J}=\mathrm{a}_{\mathrm{r} 22} \mathrm{I}+\mathrm{a}_{122} \mathrm{~J} \\
& \mathrm{~B}=1 /\left(\sigma \mathrm{L}_{\mathrm{s}}\right) \mathrm{I}=\mathrm{b}_{1} \mathrm{I} \\
& \sigma=\left(\mathrm{L}_{\mathrm{s}} \mathrm{L}_{\mathrm{r}}-\mathrm{L}_{\mathrm{m}}^{2}\right) / \mathrm{L}_{\mathrm{r}} \\
& \mathrm{I}=\left[\begin{array}{cc}
1 & 0 \\
0 & 1
\end{array}\right], \quad \mathrm{J}=\left[\begin{array}{cc}
0 & -1 \\
1 & 0
\end{array}\right]
\end{aligned}
$$

The full order state observer which estimates the stator current and rotor flux is written as follows:

$$
\left[\begin{array}{c}
\dot{\hat{i_{s}}} \\
\dot{\hat{\phi}_{\mathrm{r}}}
\end{array}\right]=\left[\begin{array}{ll}
\mathrm{A}_{11} & \mathrm{~A}_{12} \\
\mathrm{~A}_{21} & \mathrm{~A}_{22}
\end{array}\right]\left[\begin{array}{l}
\hat{\mathrm{i}}_{\mathrm{s}} \\
\hat{\phi}_{\mathrm{r}}
\end{array}\right]+\left[\begin{array}{l}
\mathrm{B} \\
0
\end{array}\right] \mathrm{v}_{\mathrm{s}}+\mathrm{G}\left(\hat{\hat{i}_{\mathrm{s}}}-\mathrm{i}_{\mathrm{s}}\right)
$$

Where ' ${ }^{\wedge}$, refers to estimated values. The poles of the observer are set proportional to those of the IM. Then the gain matrix ' $G$ ' is calculated as follows.

$$
\begin{aligned}
& \mathrm{G}=\left[\begin{array}{cccc}
\mathrm{g}_{1} & \mathrm{~g}_{2} & \mathrm{~g}_{3} & \mathrm{~g}_{4} \\
-\mathrm{g}_{2} & \mathrm{~g}_{1} & -\mathrm{g}_{4} & \mathrm{~g}_{3}
\end{array}\right]^{\mathrm{T}} \\
& \mathrm{g}_{1}=(\mathrm{k}-1)\left(-\mathrm{a}_{\mathrm{r} 11}-\mathrm{a}_{\mathrm{r} 22}\right), \mathrm{g}_{2}=(\mathrm{k}-1)\left(-\mathrm{a}_{122}\right) \\
& \mathrm{g}_{3}=\left(\mathrm{k}^{2}-1\right)\left(\mathrm{c} \mathrm{a}_{\mathrm{r} 11}-\mathrm{a}_{\mathrm{r} 21}\right)+\mathrm{c}(\mathrm{k}-1)\left(-\mathrm{a}_{\mathrm{r} 11}-\mathrm{a}_{\mathrm{r} 22}\right) \\
& \mathrm{g}_{4}=\mathrm{c}(\mathrm{k}-1)\left(-\mathrm{a}_{122}\right), \mathrm{c}=-\left(\sigma \mathrm{L}_{\mathrm{S}} \mathrm{L}_{\mathrm{r}}\right) / \mathrm{L}_{\mathrm{m}}
\end{aligned}
$$

where ' $\mathrm{K}$ ' is the proportional constant. The stator resistance and the rotor time constant, which vary with the motor temperature, are identified as follows.

$$
\begin{gathered}
\frac{\mathrm{d}}{\mathrm{dt}} \hat{\mathrm{R}}_{\mathrm{s}}=-\lambda_{1}\left(\mathrm{e}_{\mathrm{i} \alpha \mathrm{s}} \hat{\mathrm{i}}_{\alpha s}+\mathrm{e}_{\mathrm{i} \beta \mathrm{s}} \hat{\mathrm{i}}_{\beta s}\right) . \\
\frac{\mathrm{d}}{\mathrm{dt}}\left(1 / \hat{\tau}_{\mathrm{r}}\right)=\lambda_{2} / \mathrm{L}_{\mathrm{r}}\left(\mathrm{e}_{\mathrm{i} \alpha s}\left(\hat{\phi}_{\alpha r}-\mathrm{L}_{\mathrm{m}} \hat{\mathrm{i}}_{\alpha s}\right)+\mathrm{e}_{\mathrm{i} \beta \mathrm{s}}\left(\hat{\phi}_{\beta r}-\mathrm{L}_{\mathrm{m}} \hat{\mathrm{i}}_{\beta s}\right)\right) .
\end{gathered}
$$

Where, $e_{i \alpha s}=i_{\alpha s}-i_{\alpha s}^{\wedge}, \quad e_{i \beta s}=i_{\beta s}-i_{\beta s}^{\wedge}$,

$\lambda_{1}$ and $\lambda_{2}$ are positive gains, $\hat{\mathrm{i}}_{\alpha \mathrm{s}}, \hat{\mathrm{i}}_{\beta \mathrm{s}}, \hat{\phi}_{\alpha \mathrm{r}}, \widehat{\phi}_{\beta \mathrm{r}}$ are the estimated stator currents and rotor fluxes, respectively. $\tilde{\dot{i}}_{\alpha s}, \tilde{\dot{i}}_{\beta s}, \tilde{\phi}_{\alpha r}, \tilde{\phi}_{\beta r}$ are the difference between the real and estimated values of stator currents and rotor fluxes.

Fig. 6 shows the block diagram of parameters adaptive observer. Fig. 7 shows the simulated and experimental results of the parameters adaptation. Ratings of the tested induction motor are provided in Table III in Section VI. An initial value of the estimated stator resistance is 1.3 time as much as the actual value. An initial value of the estimated rotor resistance is 1.4 time as much as the actual value. Constants $\lambda 1$ and $\lambda 2$ are

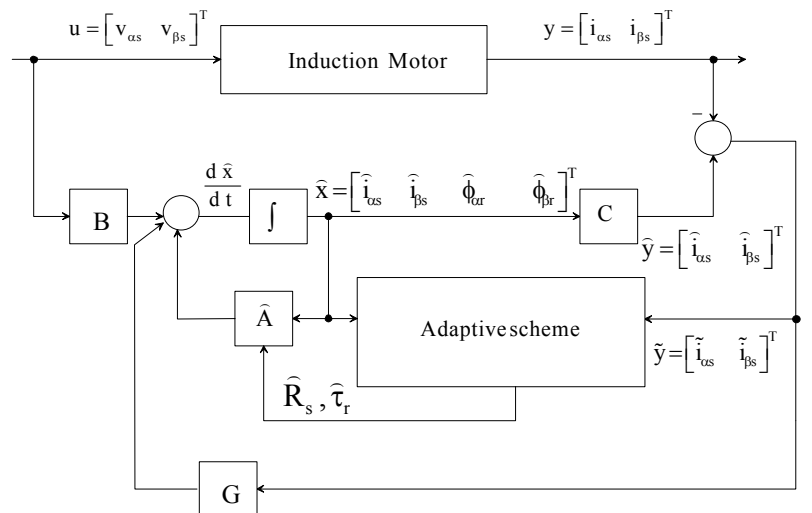

Fig. 6. Block diagram of parameter adaptive observer.

0.05 and 0.2 , respectively, and ' $k$ ' is equal to 1 . When the gain matrix ' $\mathrm{G}$ ' is zero, the motor model is simple and stable.

\section{FUZZY LOGIC SPEED CONTROLLER}

In the next sections, the simulation and experimental results will prove that controlling the motor by the optimal flux will improve the motor efficiency compared to rated flux control. On the other hand, rated flux control has better transient speed performance compared to the optimal flux control [1], [22]. To overcome the transient speed performance in optimal flux control, a fuzzy logic control (FLC) is employed [19]-[23] instead of the PI controller. The FL controller and PI controller in this implementation are shown in Fig. 8. In case of FL speed controller, there are two inputs, speed error (e) and the change in speed error $(\dot{\mathrm{e}})$. The output of the controller is the change in the reference torque producing current component $\left(\Delta \mathrm{i}_{\mathrm{qs}}^{*}\right)$.

Fig. 9 shows the FLC block diagram. The fuzzy system forms the relation between a set of inputs and a set of outputs using FL. The process consists of five sections. They are:

- $\quad$ fuzzification module (Fuzzifier).

- knowledge base.

- rule base.

- $\quad$ interface engine.

- $\quad$ defuzzification module (defuzzifier).

The input signals of the FLC in Fig. 8-b are described by triangular membership function (MF) as shown in Fig. 10. It can be noted that the triangular MFs of the input signals are not asymmetrical. The more the inputs (e and $\dot{\mathrm{e}}$ ) come closer to the origin, the more precision and accuracy will emerge [1]. In this implementation, nine fuzzy levels or sets are chosen and defined by the library of fuzzy-set values for e and ${ }^{\dot{\mathrm{e}}}$ as shown in Table I. The universe (of the discourse of the input and output signals covering the whole region) are represented in per unit values by using Gin1 and Gin2 for the input signals and Gout for the output signal. Each of input signals (e) and 


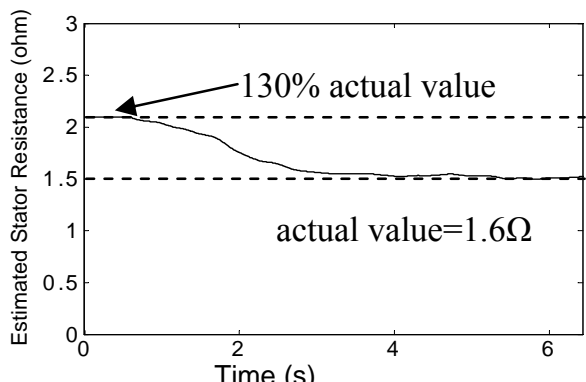

-Simulation-

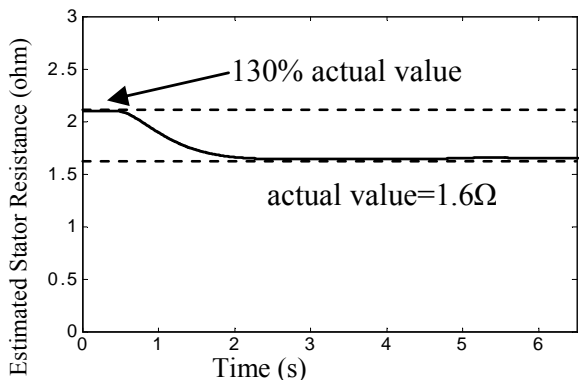

-Experimental-

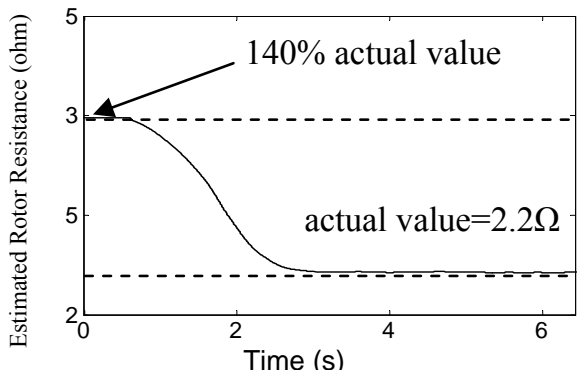

-Simulation-

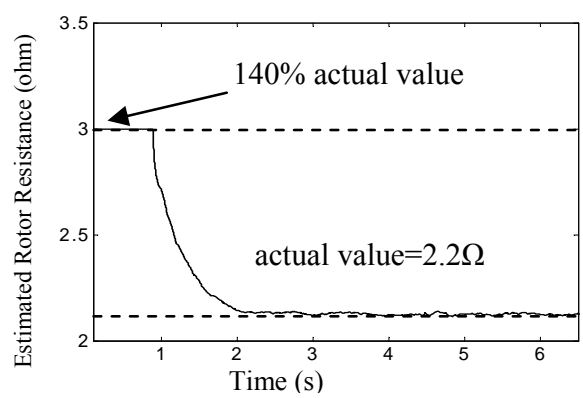

-Experimental-

Fig. 7. Estimated stator and rotor resistances.

(è ) is represented by seven MFs (NB, NM, NS, Z, PS, PM, $\mathrm{PB})$, while the output signals $\left(\Delta \mathrm{i}_{\mathrm{qS}}^{*}\right)$ is represented by nine MFs (NB, NM, NS, NVS, Z, PVS, PS, PM, PB) for more accuracy. The rules which represent the relation between the inputs and the outputs are given in Table II. The left column in Table II represents the error rate ( $\dot{\mathrm{e}}$ ) and the top row represents the error (e). The body of the table includes the MFs

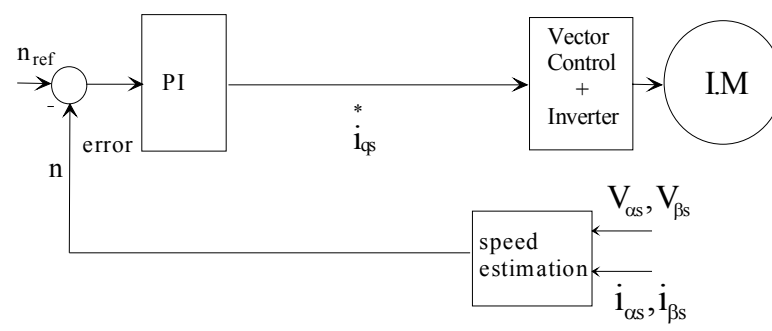

(a)

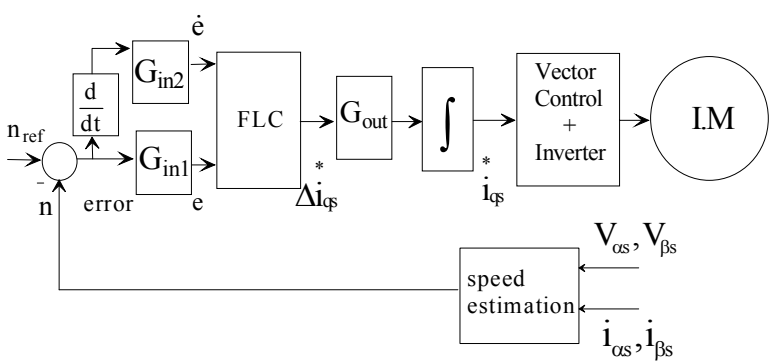

(b)

Fig. 8. Speed controlled of IM using; (a) PI. (b) FL controller.

TABLE I

FuZZY SET VALUES

\begin{tabular}{|c|c|}
\hline NB & Negative Big \\
NM & Negative Medium \\
NS & Negative Small \\
NVS & Negative Very Small \\
Z & Zero \\
PVS & Positive Very Small \\
PS & Positive Small \\
PM & Positive Medium \\
PB & Positive Big \\
\hline
\end{tabular}

of the output signal $\left(\Delta \mathrm{i}_{\mathrm{qS}}^{*}\right)$.

According to the written 49 rules in the Table II, the output signals $\left(\Delta \mathrm{i}_{\mathrm{qS}}^{*}\right)$ versus the input signals $(\mathrm{e})$ and $(\dot{\mathrm{e}})$ can be constructed as shown in Fig. 11. Some of the facts can be summarized as follows:

-When the difference between the reference speed and the measured speed (error) is negative big (NB) (beginning of the shot) and the rate of change of error is negative big (NB), the fuzzy controller should reduce the controlled current with big percent (NB) to reduce the speed.

-When the measured speed begins in reduction but its values are greater than the reference value (the error signal is negative big (NB) but the change of error is positive). In this case, if the change of error was slightly small (PS), the current should be reduced but with medium rate (NM). 


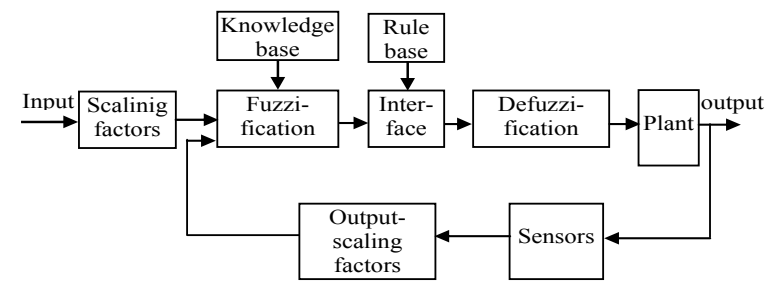

Fig. 9. FLC block diagram.

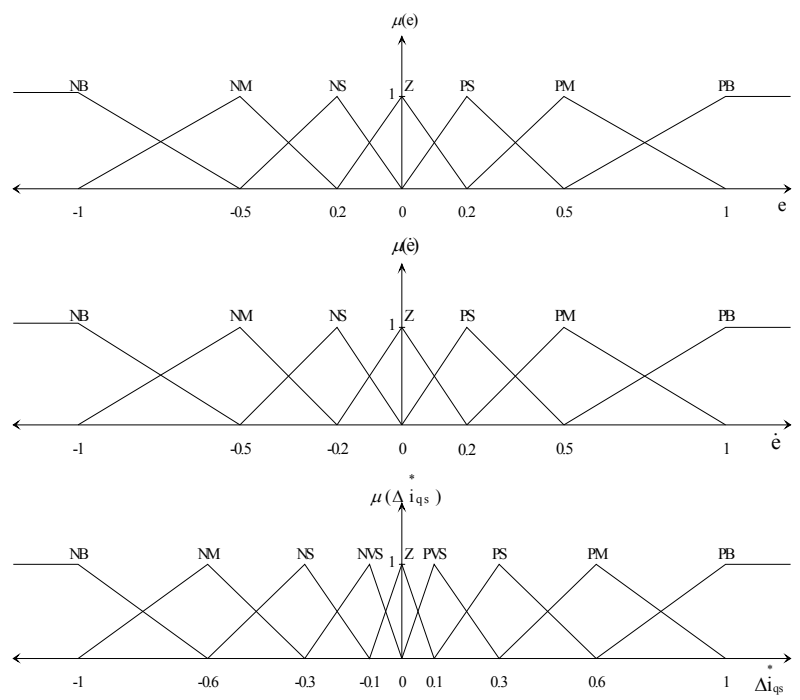

Fig. 10. Fuzzy speed control MFs. (a) Error (e), (b) Error rate $(\dot{e})$, and $(\mathrm{c})$ changing of reference current producing torque component $\left(\Delta \mathrm{i}_{\mathrm{qs}}^{*}\right)$.

TABLE II

Rule OF FuZZY SPEED CONTROLleR

\begin{tabular}{|c|c|c|c|c|c|c|c|}
\hline & NB & NM & NS & Z & PS & PM & PB \\
\hline NB & NB & NB & NB & NB & $\mathrm{NM}$ & $\mathrm{NS}$ & $\mathrm{Z}$ \\
\hline $\mathrm{NM}$ & NB & NB & NB & $\mathrm{NM}$ & NS & Z & PS \\
\hline NS & $\mathrm{NB}$ & NB & NS & NS & Z & PS & PM \\
\hline Z & NB & NM & NS & $\mathrm{Z}$ & PS & PM & PB \\
\hline PS & $\mathrm{NM}$ & NS & Z & PS & PM & PB & PB \\
\hline $\mathrm{PM}$ & NS & Z & PM & PM & PM & PB & PB \\
\hline PB & $\mathrm{Z}$ & PS & PM & PB & PB & PB & PB \\
\hline
\end{tabular}

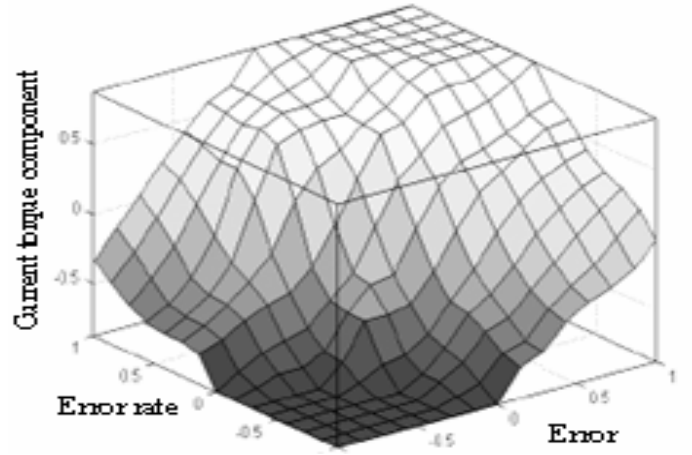

Fig. 11. The output signal ( $\left.\Delta \mathrm{i}_{\mathrm{qs}}^{*}\right)$ versus the input signals (e), and ( $\dot{\mathrm{e}})$.

\section{Simulation Results}

Before testing this controller on the real machine, a comparison between a PI controller and FL controller is done by using MATLAB fuzzy logic toolbox. The rules are chosen as explained in the previous section. The membership function editor is used to implement the proposed fuzzy logic speed controller and the triangular function is chosen to represent the two input signals (the speed error and the error rate) and the output signal (the change of reference torque producing a current component).

Advantages of the proposed LMC have been tested by running the IM with the proposed controller. Fig. 12 shows the motor efficiency by measuring the electrical and mechanical powers for different load torques up to $75 \%$ of rated value and different controlled reference speeds $(300,900$, and $1500 \mathrm{rpm})$. At $75 \%$ of rated load torque, the optimal flux is 1 p.u. as the motor is designed to give higher efficiency at $75 \%$ of rated load torque. It should be noted that, when the load torque is over $75 \%$, the calculated optimal flux value will be fixed at 1 p.u. to avoid the high overshoot or under damped oscillation of motor speed, especially if there is a sudden load change higher than $75 \%$ rated load torque. This is attributed to the sensorless speed. The motor efficiency is higher when the motor is controlled using optimal flux compared with using the rated value.

For example, at $1500 \mathrm{rpm}$ as reference speed and 0.2 p.u. of load torque, the improvement in efficiency is more than $10 \%$. For the same load torque but at $300 \mathrm{rpm}$ reference speed, the efficiency improvement increases and reaches 15\% compared with using the rated flux. Using the proposed loss model improve the motor efficiency as the load torque is adjusted to be less than $75 \%$ of the rated torque. Beyond this percentage, the motor works with rated flux.

Fig. 13 shows the simulated motor input power, motor load torque, motor speed, and reference current producing flux component. First, the reference current producing flux component and the mechanical load are set to rated value (2.9A) and zero, respectively. After $\mathrm{t}=0.6 \mathrm{~s}$, the reference current producing flux component is reduced to the calculated optimal value, so the saving in the consumed motor input power is reached approximately $42 \%$. At $\mathrm{t}=1.2 \mathrm{~s}$, while the motor is controlled with optimal flux, the load is suddenly loaded with $50 \%$ of the rated load. Thus the reference flux producing current component is increased to the rated value to face the sudden increase in the load torque. At $t=1.6 \mathrm{~s}$, it is reduced to the new calculated optimal value and the improvement in the efficiency is found to be approximately $5 \%$.

To compare between the performance of the PI and FL controllers, the gain of each controller is tuned to give the same percentage overshot at starting. Both controllers have been subjected to the same value of step change at steady-state. Fig. 14 shows the speed curves by using the PI and FL controllers. 


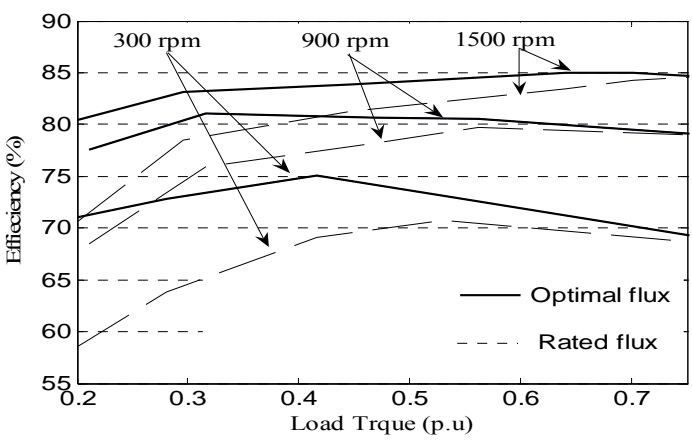

Fig. 12. Motor efficiency for different speeds and different load torques.
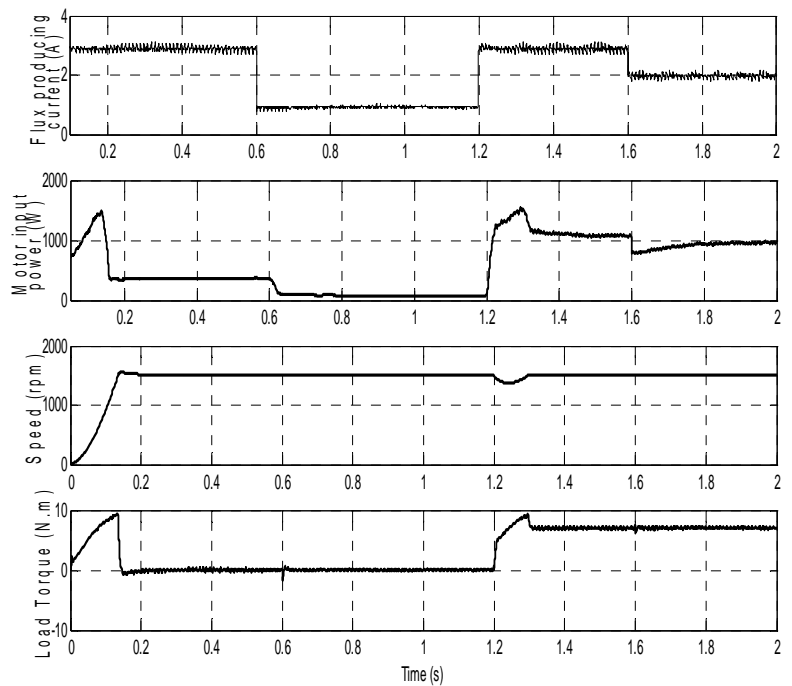

Fig. 13. Simulation results of flux producing current component, motor input power, speed, and load torque with rated and optimal flux at load changing from no load to $50 \%$.

The two controllers give the same percentage of overshoot $(0,667 \%)$. At steady state, the load torque has suddenly changed from 0.2 p.u. to 0.5 p.u. at about $3.8 \mathrm{sec}$ from the starting time. It can be noted that, the FL has a better performance compared to the PI controller.

In Fig. 15, the slopes of curve 2 (associate to the PI controller) and curve 3 (associated to the FL controller) are the same. This means that the gains of the FLC are tuned to give the same speed tracking as the PI controller. After that, the gain of the FLC, are tuned to give less slope (curve 1 for getting fast speed tracking), and higher slope (curve 4 for slow speed tracking). Still in all three cases of FLC, the percentage of overshoot is very small compared with the PI controller which confirms that the performance of the FL controller is better than the PI controller. This explained method of tuning the gains of FLC is called the "simple off-line" method. It verifies fast speed tracking without the

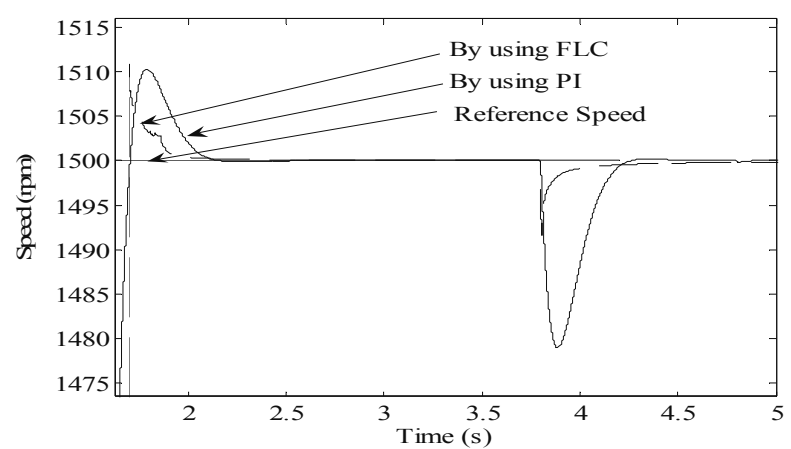

Fig. 14. Simulated motor speed during step load changing, using PI and FL controller.

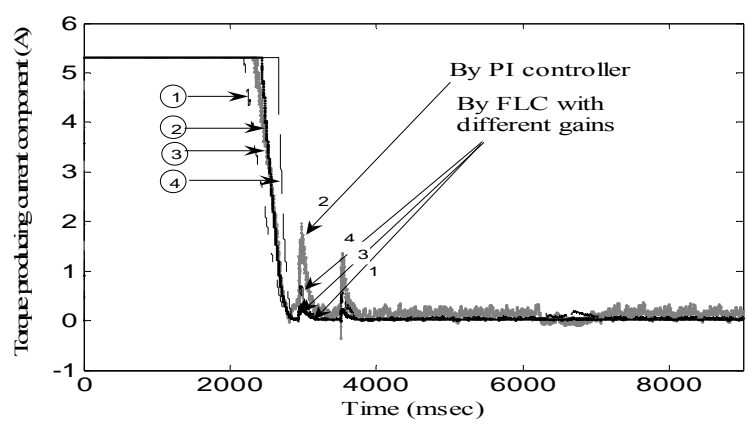

Fig. 15. The simulated reference torque producing current component (the output of PI and FL speed controller).

requirement to tune the gains several times using the motor on-line.

\section{EXPERIMENTAL RESULTS}

To validate the proposed control performance, an experimental prototype of the proposed system has been built, experimentally tested, and compared with the simulation results. A three-phase $2.2 \mathrm{~kW}$ induction motor with parameters given in table III is used. The inverter circuit was built using the intelligent power module (IPM) as switches. The inverter switching frequency is $10 \mathrm{kHz}$.

The experimental set-up is shown in Fig. 16. The tested IM is loaded with a DC generator. The coupling between the IM motor and the DC generator is done through the torque meter. The proposed control algorithm was tested within a PC under RTAI-Linux. The accuracy of the power meter and the torque meter used in measuring the electrical power and the mechanical power to calculate the motor efficiency verifies the recommendation of IEEE 112B [24].

The capacitance value of the DC Link was calculated according to (42). The discharge time (Tc) for industrial inverters at $400 \mathrm{~V}$ main supply via line-commutated converter in the power range between 10 and $40 \mathrm{kVA}$ is typically 
TABLE III

RATINGS Of THE TESTED 2.2KW INDUCTION MOTOR

\begin{tabular}{|c|c|c|c|}
\hline Rated voltage & $360 \mathrm{~V}$ & Stator inductance & $17 \mathrm{mH}$ \\
Rated current & $6 \mathrm{~A}$ & Rotor inductance & $17 \mathrm{mH}$ \\
Stator resistance & $1.6 \Omega$ & Rated speed & $1420 \mathrm{rpm}$ \\
Rotor resistance & $2.1 \Omega$ & Moment of inertia & 0.00479 \\
frequency & $50 \mathrm{~Hz}$ & Insulation class & $\mathrm{kgm}^{2} \mathrm{~F}$ \\
\hline
\end{tabular}

between $13 \mathrm{~ms}$ and $42 \mathrm{~ms}$ [25]. A discharge time of $30 \mathrm{~ms}$ was obtained after calculation of the ripple current induced from the rectifier side and the inverter side.

$$
\mathrm{T}_{\mathrm{c}}=\mathrm{C} \frac{\mathrm{V}_{\mathrm{dc}}}{\mathrm{I}_{\mathrm{dc}}}
$$

$\mathrm{V}_{\mathrm{dc}}:$ the dc link voltage

$\mathrm{I}_{\mathrm{dc}} \quad$ : the entire load current

Fig. 17 shows the measured motor input power, motor speed, load torque, and the reference flux producing current component. The motor runs first at no load and then the load suddenly increases to $50 \%$ of the rated load torque. At starting the motor reference flux producing current component is set to the rated value (rated flux). Once the speed has reached steady state and the optimal flux is calculated from the loss model controller, the reference flux producing current component is reduced from the rated value to the optimal one. It is notable that the absorbed motor input power is reduced by $40 \%$ at optimal flux compared to the rated flux operation. While the motor is controlled by optimal flux, the motor is suddenly loaded with $50 \%$ of the rated load (after $12.5 \mathrm{sec}$ from the starting time). The reference flux producing current component is increased to the rated value to face the sudden increase in the load torque. Three seconds later, it is reduced to the new calculated optimal value, and the improvement in the efficiency is $4.5 \%$.

When the optimal flux is less than the rated value, an improvement in motor power factor is achieved. Fig. 18 shows the reduction in the absorbed reactive power as the flux reduces from the rated value to the optimal one. This test was done experimentally by using power meter (LMG450) to measure the reactive power while the flux is reduced from the rated value to the optimal one for different constant load torques. The improvement in the motor power factor for different load torques and speeds is shown in Fig. 19.

The FLC was also tested experimentally and compared with the PI controller. This test was done while the motor is sensorless controlled. Fig. 20 shows the measured speed in case of using both the PI and FLC during start-up and step load change from 0.2 p.u. to 0.5 p.u. of load torque. It should be noted that the two controllers have been tuned to give the same overshoot. In case of FL, the reduction in speed is around $50 \%$ of the reduction using the PI controller. As

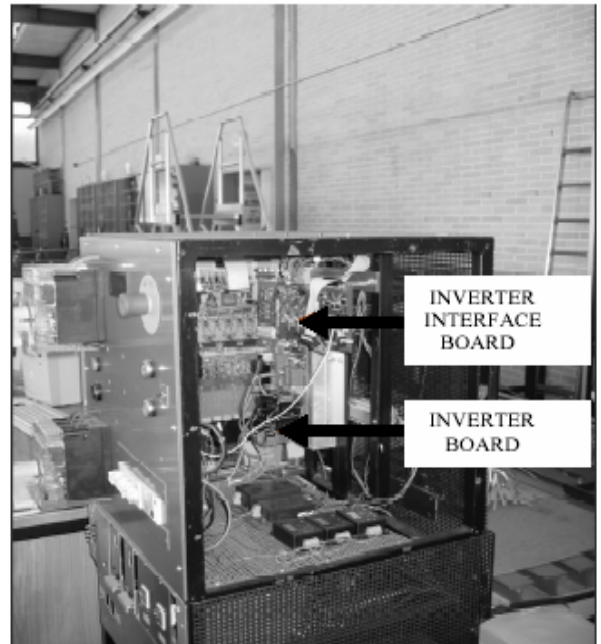

(a)The designed cabinet contains inverter board, interface board

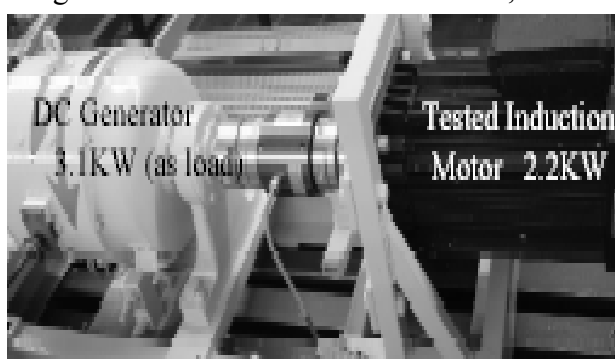

(b) The I.M coupled with DC machine through torque meter Fig. 16. The Experimental Set-Up.
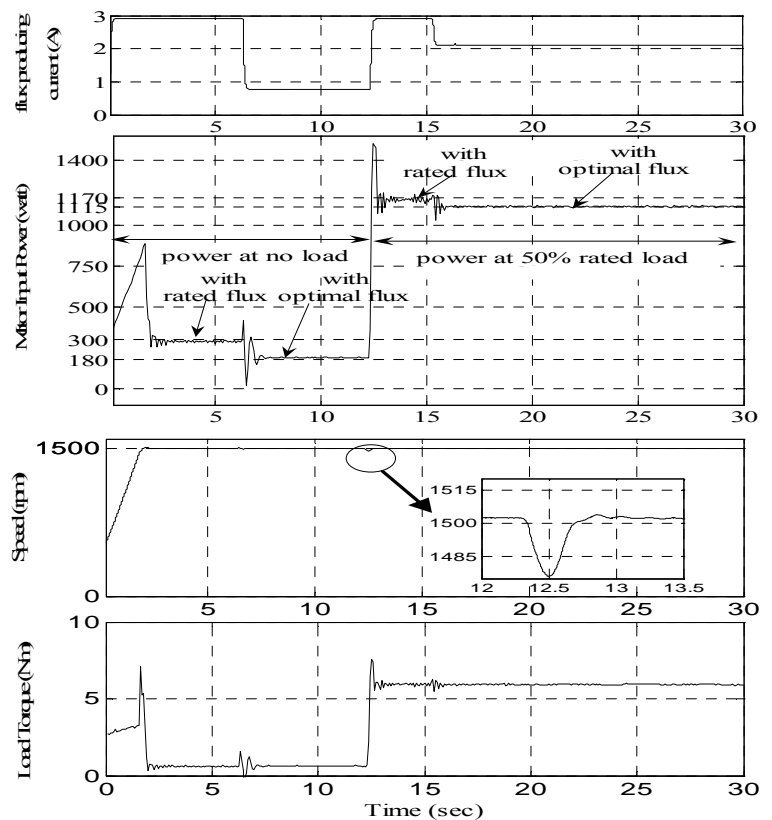

Fig. 17. Measured flux producing current component, motor input power, speed, and load torque with rated and optimal flux at load changing from no load to $50 \%$.

mentioned previously, the two controllers are tuned to give the same overshoot percentage. In this curves, the speed 


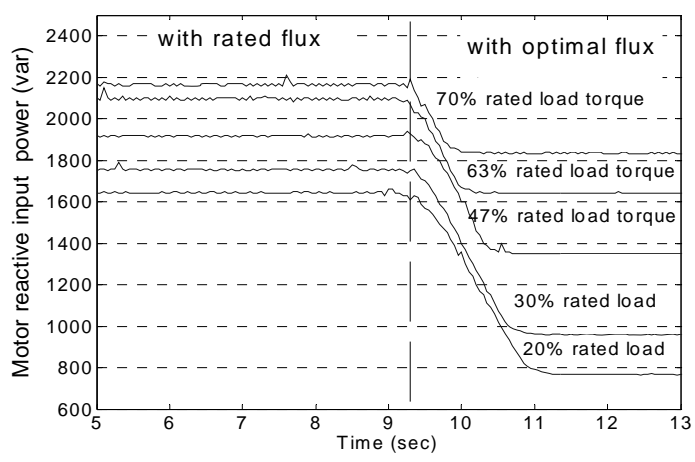

Fig. 18. Motor input reactive power with rated and optimal flux for different load torques, 1500-rpm reference speed.

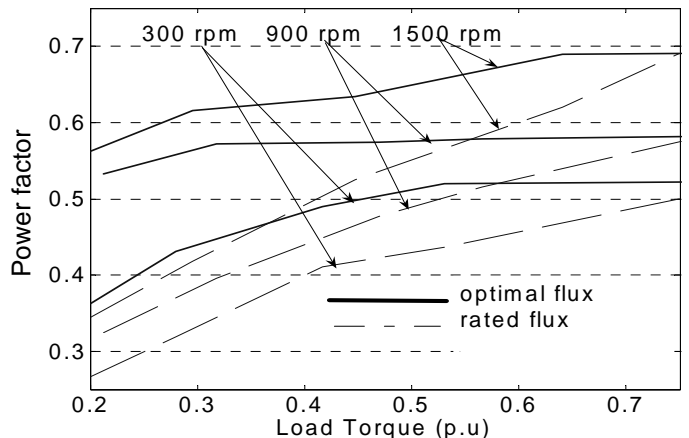

Fig. 19. Motor Power factor with rated and optimal flux for different load torques, and speeds.

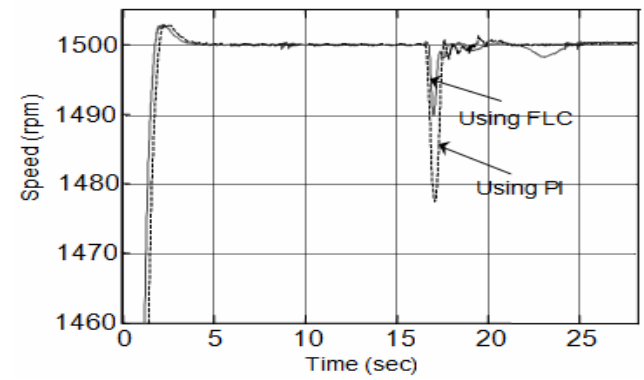

Fig. 20. Measured motor speed during step load change, using PI and FL controllers.

starting point of each test differs from the other because the experimental test duration time is not equal.

It can be concluded that the experimental results are well matched to the simulation results. The PI controller performs satisfactorily during transient with a limited operating range. Since PI controller is based on a linear model, response for large signal disturbance (i.e step load changing from 0 p.u. to 1 p.u.) is poor as the PI gains $K_{p}$ and $K_{i}$ are constants and they are fine tuned for specific operating condition. In this test the speed PI controller gains $\mathrm{K}_{\mathrm{p}}$ and $\mathrm{K}_{\mathrm{i}}$ are 1 and 26 , respectively. In conclusion, the FL controller performs satisfactorily during transient without the limited operating range.

\section{CONCLUSION}

A simple and cheap loss model is introduced without using extra hardware. The new expression for the optimal air gap is calculated from the proposed model. Controlling the motor by the optimal flux improves the motor efficiency. Fuzzy logic control is used to improve the motor speed performance instead of a classic PI controller. A comparison between a PI controller and fuzzy logic controller was done.

Generally, the proposed control method in this paper has the following advantages:

- Improved efficiency.

- Power factor improvement.

- $\quad$ Fast tracking to the motor speed without stalling the motor with low overshot.

- Reduces the overshoot and oscillation of motor speed.

- Reduces the oscillation in the torque

The experimental results show that the improvement in the motor efficiency is done by using the proposed LM controller. Besides the Fuzzy logic control improves the motor speed performance.

\section{REFERENCES}

[1] B. K.Bose, Modern Power Electronics And Ac Drives, Printed Hall PTR 2002.

[2] P. S. Andersen, D. G. Dorrell, N. C. Weihrauch, and P. E. Hansen., "Synchronous torques in split-phase induction motors," IEEE Trans. Ind. Appl., Vol. 46, No. 1, pp. 220-231, Feb. 2010.

[3] E. S. Abdin, G. A. Ghoneem, H. M. M. Diab, and S. A. Deraz. "Efficiency optimization of a vector controlled induction motor drive using an artificial neural network," Industrial Electronics Society, IECON apos; 03. The 29th Annual Conference of the IEEE, Vol.3, pp. 2543-2548, Nov. 2003.

[4] D. S. Kirschen, D. W. Novotny, and T. A. Lipo. "On-line efficiency optimization of a variable frequency induction motor drive," IEEE Trans. Ind. Appl., Vol. IA-21, No. 4, pp. 610-616, May/Jun. 1985.

[5] F. Abrahamsen, F. Blaabjerg, J. K. Pedersen, and Paul Thoegersen . "On the energy optimized control of standard and high- efficiency induction motors in CT and HVAC applications," IEEE Industry Applications Conference, Thirty-Second IAS Annual Meeting 1997, Vol. 1, pp. 621-628, Oct. 1997.

[6] F. Abrahamsen, F. Blaabjerg, J. K. Pedersen, and Paul B. Thoegersen, "Efficiency-optimized control of medium-size induction motor drives," IEEE Trans. Ind. Appl., Vol. 37, No. 6, Dec. 2001.

[7] F. Fernandez-Bernal, A. Garcia-Cerrada, and R. Faure, "Model-based loss minimization for $\mathrm{dc}$ and ac vector controlled motors including core saturation," IEEE Industry Applications Conference, Thirty-Fourth Annual Meeting, Vol. 3, pp. 1608-1615, Oct. 1999.

[8] G. O. Garcia, J. C. M. Luis, R. M. Stephan, and E. H. Watanabe, "An efficient controller for an adjustable speed induction motor drive," IEEE Trans. Ind. Electron., Vol. 41, No. 5, pp. 533-539, Oct. 1994.

[9] I. Kioskeridis and N. Margaris. "Loss minimization in induction motor adjustable-speed drives," IEEE Trans. Ind. Electron., Vol. 43, No. 1, pp. 226-231, Feb. 1996.

[10] M. Mannan, T. Murata, J. Tamura, and T. Tsuchiya, "Energy model based loss-minimized speed control of 
induction motor with a full-order observer," IEEJ Transactions 2006, Vol. 1, pp. 35-44, 2006.

[11] S. Lim and K. Nam. "Loss-minimizing control scheme for induction motor," IEE Proceeding, Vol. 151, Issue 4, pp. 385-397, Jul. 2004.

[12] M. Hajian, J. Soltani, G. A. Markadeh, and S. Hosseinnia, "Adaptive nonlinear direct torque control of sensorless IM drives with efficiency optimization," IEEE Trans. Ind. Electron., Vol. 57, No. 3, pp. 975-985, Mar. 2010.

[13] C. Chakraborty and Y. Hori. "Fast efficiency optimization techniques for the indirect vector-controlled induction motor drives," IEEE Trans. Ind. Appl., Vol. 39, No. 4, pp. 1070-1076, Jul. 2003.

[14] H. Kubota and K. Matsuse, "Speed sensorless field-oriented control induction motor with rotor resistance adaptation," IEEE Trans. Ind. Electron., Vol. 30, pp. 1219-1224, Sep./Oct. 1994.

[15] E. Hussein and P. Mutschler "Optimal flux loss model based speed sensorless control of induction motor," IEEE, PEMD 2010, pp. 1-6, Apr. 2010.

[16] E. Hussein and P. Mutschler "Improving and Measuring the efficiency of the speed sensorless vector controlled induction motor," IEEE, OPTIM 2010, pp. 681-688, May 2010.

[17] E. Hussein and P. Mutschler "Improving the efficiency for speed sensorless indirect field oriented control induction motor," IEEE, EPE-PEMC 2010,pp. 136-141, Sep. 2010.

[18] O. Ojo and G. Dong, "Sensorless control of induction motor using natural variables with loss minimization," Applied Power Electronic Conference and Exposition, APEC 2005, Vol. 1, pp. 451-457, Mar. 2005.

[19] A. M. Eltamaly, A. I. Alolah, and B. M. Badr, "Fuzzy controller for three phases induction motor drives," IEEE Autonomous and Intelligent Systems (AIS) 2010, Vol. 1, pp. 1-6, Aug. 2010.

[20] D. Asija, "Speed control of induction motor using fuzzy-PI controller," Mechanical and Electronics Engineering (ICMEE), Vol. 2, pp. 460-463, Aug. 2010.

[21] M. Ben Hamed and L. Sbita, "Fuzzy logic speed controller for direct vector control of induction motor," International Journal of Electrical and Electronics Engineering, pp. 449-455, Jul. 2009.

[22] K. R. Kumar, D. Sakthibala, and S. Palaniswami, "Efficiency optimization of induction motor drive using soft computing techniques," International Journal of Computer Application, Vol. 3, No. 1, Jun. 2010.

[23] M. N. Uddin and R. S. Rebeiro, "Online efficiency optimization of a fuzzy-logic-controller-based IPMSM drive," IEEE Trans. Ind. Appl., Vol. 47, No. 2, pp. 1043-1050, Apr. 2010.

[24] "IEEE Standard Test Procedure for Polyphase Induction Motors and Generators," IEEE Std.112, 1996.

[25] H. Lamsahel, P. Mutschler, and M. Reddy, "Controlling voltage source converters with minimal energy storage," European Conference on Power Electronics and Applications, pp. 9-18, 2005.

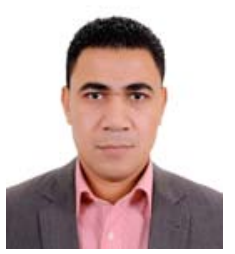

Emad Abdelkarim was born in Qena, Egypt, in 1977. He received the B.S. and M.Sc. degrees from South Valley University, Aswan, Egypt in 2000 and 2005 respectively. In 2011, he obtained his $\mathrm{PhD}$ from Darmstadt University of Technology, Darmstadt, Germany. He is currently a member of APEARC (Aswan Power Electronic Application Research Center). His research interests include power electronics; control of drive, harmonics filters analysis, renewable energy, and power quality.

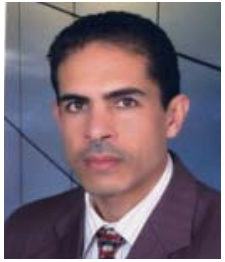

Mahrous Ahmed was born in Sohag, Egypt. He received the B.S. and M.Sc. degrees in electrical engineering from Assiut University, Assiut, Egypt, in 1996 and 2000, respectively, and the Ph.D. degree in electrical engineering from University of Malaya, Kuala Lumpur, Malaysia, in 2007. Since 2007, he has been an assistant professor with the Aswan Faculty of Engineering, South Valley University, Aswan, Egypt. In 2008, he joined Aswan Power Electronics applications research center. Currently, he is an assistant professor at faculty of engineering, Taif University, KSA. His research interests are power electronics and real time control systems.

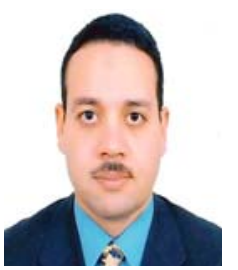

Mohamed Orabi (SM'08) received the M.S. degree from El-Minia University, El-Minia, Egypt, in 2000, and the Ph.D. degree from Kyushu University, Fukuoka, Japan, in 2004. $\mathrm{He}$ is currently the Vice Dean of Aswan Faculty of Engineering for Graduate Studies and the Director of the Aswan Power Electronics Application Research Center, Faculty of Engineering, South Valley University, Aswan, Egypt. He has published more than 120 papers in international conferences and journals. His research interest includes power electronics applications and renewable energy applications. Dr. Orabi is a Reviewer for the IEEE Power Electronics Society (PELS), IEEE Industry Applications Society, IEEE Industrial Electronics Society (IES), IEEE Circuits and Systems Society, and IET-PE Transactions and Conferences. Dr. Orabi has received the South Valley University Encouragement Award in 2009 and the National Encouragement Award in 2010 for his great achievements in the field of engineering and science.

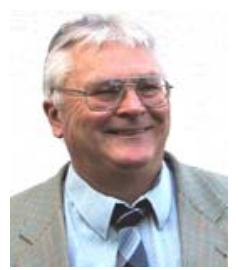

Peter Mutschler was born in 1944 and studied electrical and control engineering at Darmstadt University of Technology, Germany from 1964 to 1969. Afterwards, he became a research engineer at the institute of power electronics and drives. The area of his research was High Voltage Direct Current Transmission (HVDC). In 1975, he received the Ph.D. degree with a thesis on HVDC-Problems. Then he moved to Brown Boveri Company in Mannheim, where he worked in an R\&D department. He mainly developed micro-processor based controls and protection equipments for a large variety of applications, including HVDC, converter - fed drives for railways and trams, motor control and battery management for electric cars and OEM converters for general industrial applications. In 1988, he became a university professor and took over the chair of power electronics and drives at Darmstadt University of Technology. His research activities include: linear drives, sensorless controls. 